\title{
Re-UCP Effort Estimation for Web Application Evelopment
}

\author{
MUDASIR M. KIRMANI \\ Computer Science Sher-e-Kashmir University of Agricultural \\ Sciences \& Technology of Kashmir Srinagar, J\&K, India.
}

\begin{abstract}
Practical effort estimation is very basic and most essential aspect of very organisation to sustain better project management. Accuracy in efforts makes the organisation to surge its business and build motivation among its customers effectively. It was observed that continuous improvement is required for software effort assessment after regular eras. The fundamental point of this examination work is to assess the execution of Re-UCP strategy for estimation of efforts for web application projects. This research work compares the existing effort estimation model results with the Re-UCP effort estimation methods results for web application development projects.
\end{abstract}

\section{(1) \\ Article History \\ Received: 19 May 2017 Accepted: 15 June 2017}

\section{Keywords}

Software effort

Estimation

Web Engineering,

Web effort

estimation.

\section{Introduction}

The implementation of software application have become so ubiquitous that all the organisation have switched their work environment on online media. For software development companies the most critical and challenging aspect is that there is no standardized measure to approximate software efforts for a software development project. This issue has put the cutting edge software development organizations in a circumstance wherein they are managing ill-advised requirement engineering, vague asset elicitation, unverifiable cost and effort estimation.
This has become now the primary approach of every software industry to design better software management system so that all the aspects needed for a software development project, can be systematized to produce effective results by proposing accurate budget and financial inputs needed for the software development project ${ }^{1,2}$. The systemized approach of estimating the resources needed for the software development project in early phases of software development process makes it possible to check the feasibility of the conceived developmental assignment. To understand the basic functionality of the software application to be

CONTACT Mudasir M. Kirmani \& Technology of Kashmir Srinagar, J\&K, India.

(C) 2017 The Author(s). Published by Techno Research Publishers

This is an $\mathbf{6}$ Open Access article licensed under a Creative Commons Attribution-NonCommercial-ShareAlike 4.0 International License (https://creativecommons.org/licenses/by-nc-sa/4.0/), which permits unrestricted NonCommercial use, distribution, and reproduction in any medium, provided the original work is properly cited.

To Link to this Article: http://dx.doi.org/10.13005/ojcst/10.04.08 
developed by using objective oriented design is by implementing use case diagrams. Use case diagrams are very easy to implement and very popular to map the functionality of the software application after properly understanding user requirements. ${ }^{6,7}$. The easiness and popularity of use case diagrams have made useful tools for approximating the estimates needed for the software development project ${ }^{3}$. In this study detailed description and overview of Revised Use Case Points (Re-UCP) method for estimating the effort needed for development of software project in its early stages of development ${ }^{15}$.A new method based on use case points obtained from different use case scenarios called as revised use case points is proposed to estimate software efforts effectively.

In this research study an effort has been made to evaluate the relevance of Re-UCP technique of estimating efforts for web application development. This examination work is a push to assess the $n$ effort to evaluate execution of modified use case point technique proposed by Kirmani $\mathrm{M} \mathrm{M}^{15}$ software estimation method for web application development with the existing method of effort estimation of web projects in a company for six different real time projects.

Six real time project from a software development company in Jammu and Kashmir were selected for the comparison. The comparison of the results related to six web application development projects shows that Re-UCP technique has not performed better than the existing method of effort estimation used by the organization.

\section{Re-UCP Technique}

In Re-UCP based technique the estimation of the software application is measured by assessing the appoximate number of use-case-scenarios within a software application to be developed. Use cases represent the functional aspect of the software application. This usefulness of the framework is evaluated by the aggregate effect of comparing elements related with actors of the framework, conduct of use-case, effect of environmental and technical complexity parameters for a software development process.
In Re-UCP technique of approximation of efforts the actors, use-cases, environmental \& technical intricacy parameters are additionally refined with various multifaceted intricacy levels and recently proposed multiplying factors.

In Re-UCP actors are classified into four types: simple, average, complex and critical with 1, 2, 3 and 4 multiplying factor respectively while as in UCP and e-UCP actors were classified into three types. Each of these types have their respective weighting factor associated to it. The use-cases are categorised into simple, average, complex and critical with revised weight $5,10,15$ and 20 respectively. The categorization of use-cases is done based on the number of transactions in a scenario ${ }^{15}$.

Technical complexity factors (TCF) from T1 to T13 and their corresponding weighting parameters are calculated by multiplying each factor with its corresponding weight to obtain overall impact of TCF's on Software development. Environmental intricacy parameters from E1 to E9 and their corresponding weighting facts are calculated by multiplying each factor with its corresponding weight to obtain overall impact of ECF's on Software development.

After categorization of use-cases in the different categories, the UUCP is calculated using the technique proposed $\mathrm{in}^{15}$. The final calculation of Re-UCP points is calculated using the following equation.

$R U C P=U U C P^{\star} T^{*} F^{\star} E C F$

Effort $=$ RUCP ${ }^{\star}$ PHpr Re-UCP

Where PHpr RUCP is Person Hours per RUCP

\section{Results and Discussion}

Based on the privacy policy of the software development company the effort estimation method name cannot be mentioned in this study, therefore, the method is named as existing method. The efforts calculated for six different project is given in table (1) 
Table 1: Effort estimation using Re-UCP

\begin{tabular}{lll}
\hline $\begin{array}{l}\text { Project } \\
\text { Name }\end{array}$ & $\begin{array}{l}\text { Re-UCP } \\
\text { points }\end{array}$ & $\begin{array}{l}\text { Estimated Effort } \\
\text { @20 / Re-UCP }\end{array}$ \\
\hline Proj-1 & 65 & 1300 \\
Proj-2 & 92 & 1840 \\
Proj-3 & 109 & 2180 \\
Proj-4 & 52 & 1040 \\
Proj-5 & 79 & 1580 \\
Proj-6 & 43 & 860 \\
\hline
\end{tabular}

The deviation is computed by subtracting the real efforts from the assessed efforts. In order to be more precise while comparing both the results the deviation values are changed to percentage. The Positive deviation connotes the higher estimation of assessed efforts than genuine efforts while as negative deviation clarifies that the evaluated efforts are less than the real efforts. The information identified with rate of deviation of evaluated efforts from genuine efforts for existing methods and Re-UCP technique for approximation of efforts is if there should be an occurrence of existing strategy and Re-UCP techniques for programming exertion estimation is specified in table (2).

Rate of deviation from real assessed efforts for existing method and Re-UCP technique.

Table 2: Rate of deviation from real assessed efforts for existing method and Re-UCP technique.

\begin{tabular}{lll}
\hline Name & \multicolumn{2}{l}{ Rate of Deviation } \\
\cline { 2 - 3 } & Existing method & Re-UCP \\
\hline Proj-1 & 72 & 162 \\
Proj-2 & 94 & 134 \\
Proj-3 & 90 & 240 \\
Proj-4 & 58 & 108 \\
Proj-5 & 30 & 287 \\
Proj-6 & 103 & 129 \\
\hline
\end{tabular}

The percentage of deviations using Re-UCP method against the "realassessed effort" is shown graphically in figure (1).

The graphical representation clearly shows that the Re-UCP method has not performed better than the existing method used by the web application

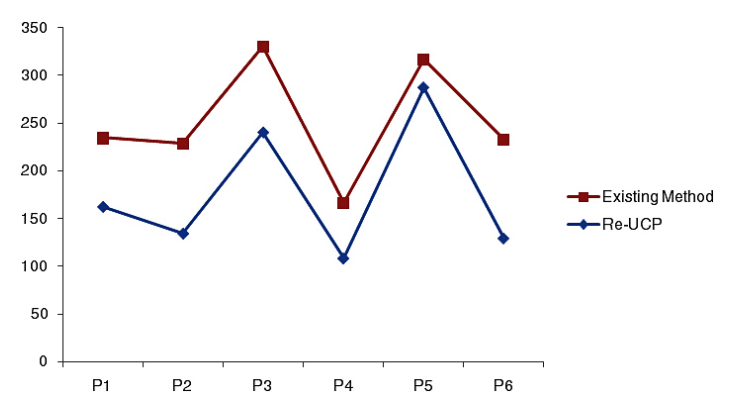

Fig. 1: Deviations using existing method and Re-UCP

development enterprises. The disparity among the actual and estimated values using Re-UCP is more when compared with the estimated values using the existing method of the software development organization.

\section{Conclusion}

The effort estimation for any web application programming development venture ought to be in the early phases of development in order to reduce the gap between the estimated effort and actual effort. To adapt to the effort assessment of the endeavors with differing intricacies Re-UCP technique is designed. The deviation from actual efforts in case of six real time projects did show better performance of Re-UCP from the existing methods used by the software development organization. However the examination of Re-UCP with the current model of the organizations should be tried with information from bigger enterprises from worldwide and national effort assessment associations. The information from software Industry may be used to further test the appraisal of evaluations utilizing Re-UCP and the present strategies for effort assessment and approximation. Hence, future research in this domain can be finished to brace the systems assessable for assessing efforts of web applications which will help the architects or specialists in decreasing the space between the real-efforts and evaluated-efforts. Regardless, the Re-UCP methodology of assessing efforts can also be investigated to suit the essentials of web application enhancement.

\section{Acknowledgement}

The author would thank Prof. Abdul Wahid, Dr. Pradeep Kumar and Mr. Ansarullah for their support in carrying out this research study. I would like to thank all the practitioners and Data Mining experts who were consulted while carrying out the research work. 


\section{References}

Alves, Rui, Pedro Valente, and Nuno Jardim Nunes. "Improving software effort estimation with human-centric models: a comparison of UCP and iUCP accuracy." Proceedings of the 5th ACM SIGCHI symposium on Engineering interactive computing systems. ACM, 2013. Anda, Bente, Endre Angelvik, and Kirsten Ribu. "Improving estimation practices by applying use case models." Product Focused Software Process Improvement. Springer Berlin Heidelberg, 2002, (pp 383-397).

3 Apol P Subraiadi, et. al., "Critical Review of the effort rate value in use case point method for estimating software development effort", Journal of Theoritical and Applied Information Technology, Vol. 59 (3), 2014, (pp. 735-744).

4 Ashman, R., Project estimation: a simple usecase-based model. IT professional, Vol. 6(4), 2004, (pp 40-44).

5 Azzeh, M., "Software cost estimation based on use case points for global software development." Computer Science and Information Technology (CSIT), 2013 5th International Conference on. IEEE, 2013, (pp 214-218).

Carroll, E. R. (2005, October). Estimating software based on use case points. In Companion to the 20th annual ACM SIGPLAN conference on Object-oriented programming, systems, languages, and applications, ACM 2005 (pp. 257-265).

7 Clemmons, Roy K. "Project estimation with use case points." The Journal of Defense Software Engineering, 2006, (pp 18-22).

8 Eberendu, A. C., Software Project Cost Estimation: Issues, Problems and Possible Solutions, International Journal of Engineering Science Invention Vol. 3(II) June 2014 SSSS(pp. 38-43)

Issa, A., Odeh, M., \& Coward, D.. Can Function Points be Mapped to Object Points?, The International Arab Journal of Information Technology, Vol. 4(1), 2007, (pp 41-49). Group. Boston. 2009 [Online]. Available:

http://www.standishgroup.com/newsroom/ chaos_2009.php.

11 Jena, P. P., \& Mishra, S. Survey Report on Software Cost Estimation using Use Case Point Method, International Journal of Computer Science \& Engineering Technology, Vol. 5 (04), 2014, (pp 280-287).

12 Jha, P., Jena, P. P., \& Malu, R. K. Estimating Software Development Effort using UML Use Case Point (UCP) Method with a Modified set of Environmental Factors, International Journal of Computer Science and Information Technologies (IJCSIT)", Vol. 5 (3) , 2014, (pp 2742-2744)

13 Jones, T. C. , Estimating software costs. McGraw-Hill, Inc. 1998.

14 Karner, G., Metrics for objectory. Sweden: University of Linköping. Sweden. No. LiTHIDAEx-9344:21.December 1993.

15 Kirmani M. M., and Wahid, A., Revised Use Case Point (Re-UCP) Model for Software Effort Estimation, International Journal of Advanced Computer Science and Applications (IJACSA), 6(3), 2015 (pp.65-71). http://dx.doi. org/10.14569/IJACSA.2015.060310

16 Kumari, S., \& Pushkar, S. (2013). Performance Analysis of the Software Cost Estimation Methods: A Review. International Journal of Advanced Research in Computer Science and Software Engineering, Vol. 3(7), 2013 (pp. 229-238).

17 Kumari, S., \& Pushkar, S. Comparison and Analysis of Different Software Cost Estimation Methods. International Journal of Advanced Computer Science and Application, vol. 4 (1), 2013.

18 Mohagheghi, Parastoo, Bente Anda, and Reidar Conradi. "Effort estimation of use cases for incremental large-scale software development." Software Engineering, 2005. ICSE 2005. Proceedings. 27th International Conference on. IEEE, 2005.

19 Nagar, C., Software efforts estimation using Use Case Point approach by increasing Technical Complexity and Experience Factors, International Journal on Computer 
Science and Engineering (IJCSE)", vol. 3 (10), 2011, (pp. 3337-3345)

Nageswaran, S., Test effort estimation using use case points. In Quality Week, 2001 (pp. 1-6).

$21 \quad$ Nassif, Ali Bou. "Enhancing Use Case Points Estimation Method using Soft Computing Techniques." Journal of Global Research in Computer Science, Vol.1 (4), 2010. (pp 12-21).

22 Ochodek M., Nawrocki, J., Kwarciak, K., "Simplifying Effort Estimation based on Use Case Points" Science direct, Elsevvier, 2011, (pp 200-213).

23 Periyasamy, K., \& Ghode, A., Cost estimation using extended use case point (e-UCP) model. In Computational Intelligence and Software Engineering, 2009. CiSE 2009. International Conference IEEE, 2009, (pp. 1-5).
Robiolo, G., \& Orosco, R. (2008). Employing use cases to early estimate effort with simpler metrics. Innovations in Systems and Software Engineering, 4(1), 2008 (pp. 31-43).

25 Robiolo, Gabriela, and Ricardo Orosco. "Employing use cases to early estimate effort with simpler metrics." Innovations in Systems and Software Engineering Vol. 4(1), 2008, (pp 31-43).

26 Ruhe, M., Jeffery, R., \& Wieczorek, I., Cost estimation for web applications. In Software Engineering, 2003. Proceedings. 25th International Conference, IEEE 2003, (pp. 285-294).

27 Schneider, G., \& Winters, J. Applying Use Cases - A Practical Guide.Addison-Wesley, 1998.

28 Standish Group, 2011, Chaos Reports http:// standish group.com/news. Retrieved on 17 Jan 2014. 